\title{
Analysis of the Development and Application of Salary Management System in China Railway Enterprises
}

\author{
Lei Ma, Chenhui Xie, Yi Chun, Chengliang Liu \\ T Department, China Academy Of Railway Sciences, Beijing, China
}

\section{Email address:}

malei@rails.cn (Lei Ma), xiechenhui@rails,cn (Chenhui Xie), chunyi@rails.cn (Yi Chun), liucl@rails.cn (Chengliang Liu)

\section{To cite this article:}

Lei Ma, Chenhui Xie, Yi Chun, Chengliang Liu. Analysis of the Development and Application of Salary Management System in China Railway Enterprises. Automation, Control and Intelligent Systems. Vol. 3, No. 5, 2015, pp. 81-86. doi: 10.11648/j.acis.20150305.14

\begin{abstract}
In this paper, the ways of salary management system in the world is be fully concerned. Combing both with the characteristics of China railway industry and the pay policies made by China-railway corporation, a salary management system of China railway enterprises is established which meet the needs of some special characteristic, such as the complex personnel structure, the variety of salary structure and the disunity distribution system. Acrossing the core rules and logic checking, the automatic calculation and distribution of salary will be realized. At the same time, there will be an effectively integration between the railway financial and accounting management system, which used in the whole railway, and the salary management system. By this way, the salary vouchers can be automatic posted to realize the integration of human resource management and financial management business.
\end{abstract}

Keywords: China Railway Enterprise, Salary Administration, the Rules,

Railway Financial and Accounting Management System

\section{浅谈中国铁路企业薪酬管理系统的研发与应用}

\author{
麻磊, 解辰辉, 春意, 刘承亮 \\ 中国铁道科学研究院电子所院信息技术中心, 北京, 中国
}

\section{邮箱}

malei@rails.cn（麻否）, xiechenhui@rails.cn（解辰辉）, chunyi@rails.cn（春意）, liuc1@rails. cn（刘承亮）

中文摘要：本文充分借鉴国际上薪酬管理系统的建设方法，结合中国铁路行业特色以及铁路总公司薪酬发放政策，建 立满足路内企业人员结构复杂、工资结构多样化、薪酬发放制度不统一等特点的中国铁路企业薪酬管理系统，通过核 心规则的制定与逻辑校验，实现员工薪酬的自动核算与发放。同时，系统能够与路内统一使用的铁路财会系统有效集 成，实现工资凭证的自动过账与人工成本核算，实现了人财业务的高度集成。

关键词: 中国铁路企业, 薪酬管理, 规则, 铁路财会系统

\section{1. 引言}

薪酬管理是目前国际上HR管理系统中非常重要的组 件功能之一。它影响到企业的发展, 涉及每一位员工的 切身利益，不同的薪酬决策会给企业带来不同的结果。 符合市场规律，符合企业实际，具有激励机制的薪酬方
案，可以极大地调动广大干部、员工的工作积极性，有 效降低工资成本，更好地提高生产效率 [1]。中国铁路企 业不同于其他国有企业，具有人员结构复杂、分类多样 化，且工资结构受到中国铁路总公司影响，具有工资项 的特殊性和发放制度不统一等特点, 再加上大部分路内 单位的工资、绩效、专项奖励等数据的获取渠道繁多, 
导致企业内部的薪酬管理难度大且流程繁琐。目前, 绝 大多数路内企业仍然采取手工EXCEL管理员工薪酬数据, 缺乏有效的管理手段和管理工具, 数据反复调整核对等 重复性事务工作极大的占据了日常薪酬管理工作的时间 和精力。同时, 无法与全路统一使用的铁路财会系统 [2] 进行有效的集成, 导致财务无法及时进行过账和核算, 极大地影响了用户的使用, 业务衔接出现断裂。

针对上述问题，本文提出对中国铁路企业实行适合 路内企业薪酬管理的系统建设方案。结合中国铁路总公 司的薪酬发放政策, 制定满足路内薪酬发放的逻辑规则, 并将业务逻辑规则有效转化为数据库可识别的SQL语句, 结合考勤、社保等数据, 实现员工薪酬数据的自动核算 与发放, 并最终将工资凭证过账给铁路财会系统进行核 算。

\section{2. 中国铁路现状分析}

\section{1. 铁路企业工资构成}

目前中国铁路总公司下属各单位, 无论铁路局还是 科研院所, 基本都存在铁路编制职工和社会招聘职工两 种。这也就造就了不同的工资制度, 本文以其中一家单 位为例，概述一下铁路企业的工资构成。

铁路编制内员工属于铁路系统正式职工，其工资结 构为四元工资制, 包括技能工资、岗位工资、津补贴和 绩效工资。其中岗位工资又包含部标岗位工资, 是根据 铁路总公司文件进行发放的 [3]。社会招聘员工不属于铁 路系统员工, 是为了满足企业经营需要招聘的社会化员 工, 其工资结构相对简单, 工资项目单一且不受到铁路 总公司的制约和影响。

\section{2 . 薪酬管理现状}

路内企业薪酬管理的难点在于人员结构复杂, 工资 制度因员工身份不同而不统一; 同时，依据铁路总公司 薪酬政策，路内企业工资项目繁多且计算规则既有按区 间档位核算的, 也有按照系数进行核算的情况, 极大地 增加了人资部门、财务部门对于员工薪酬金额的编制与 核算的难度。此外, 薪酬发放仍然依靠人工Exce1管理, 人资部将编制完成的薪酬数据Excel表格传递给财务部门, 为了确保数据的准确性，财务部往往需要花费大量时间 反复核对后再进行扣税核算，一旦人资部对金额或者工 资项目进行了临时调整, 财务部要进行重复工作, 极大 地制约了工作效率，延误薪酬发放时间的情况时有发生。

目前, 铁路总公司要求全部路内企业财务部门必须 统一使用铁路财会系统进行会计凭证、总账和明细账的 上报, 如果薪酬管理系统无法与该系统集成, 势必会导 致大量重复性工作, 例如需要重复录入员工工资会计凭 证等, 这一问题早已对路内企业财务部门困扰多年, 且 国际上很多成熟的产品是无法满足这一需求的。

\section{3. 系统建设必要性}

信息采集、保存、共享等现状问题和影响
1）业务信息保存在个人手中或部门业务应用系统中, 流程以及信息的集成性偏低, 不利于高层管控和 决策，也不利于业务协作;

2) 大量业务数据信息以纸质方式传递和保存，无法 保证标准化归档和统一管控;

3) 大部分工资数据需要手工上报, 并需要人工进行 反复核对汇总, 统计分析, 大幅增加工作量和耗 费时间;

4）需要进一步制订统一的信息标准及数据定义，促 进各部门内部以及部门间的信息传递和共享;

5）各种管理、业务信息，如：统计报表、工资条等 信息还需要规范共享的流程和权限;

6）内部信息没有做到就源输入，根据业务和管理需 要按权限共享, 而是谁用要谁收集, 不利于管理 和保密;

7）由于工资数据信息分散存储, 信息未能进行整合, 使数据的准确性和版本统一很难实现;

8) 难于进行整体跨部门的汇总信息分析;

综上所述，建立一套适合中国铁路企业的，且充分 适应铁路总公司工资政策和业务需求，满足多元工资制 度, 通过铁路财会系统将人资和财务薪酬管理业务有效 集成在一起的薪酬管理系统迫在眉睫。

\section{3. 软件需求}

\section{1 . 安全需求}

1) 具有密码管理功能, 对用户密码的长度、复杂性、 有效期有限制和提醒功能 [4];

2) 提供日志功能, 即利用各种手段来记录用户对系 统的各种操作, 来跟踪指定用户的操作以及对系 统进行的变更, 只有相应的授权用户和管理员可 以查看这些日志进行分析和监控; 系统对所有人 员的操作日志都应进行详细记录, 并提供统计、 查询、打印等;

3) 系统必须支持数据备份与恢复机制;

4) 对授权操作可以有效地追溯其更改历史纪录;

5) 必须支持数据库密文存储;

6) 系统支持异常报警功能, 系统出现的任何异常能 够以邮件形式发送系统管理员。

\section{2. 性能需求}

(1) 可用性需求

1) 持续工作时间: 本系统为在线事务处理系统, 要 求连续不间断的 ( $7 \times 24$ 小时) 持续工作;

2) 有效工作时间：系统应至少保证 $99.9 \%$ 的工作时 间正常运作;

3) 在线事务响应时间: 系统平均响应时间应低于 3 秒, 最长响应时间应不超过 7 秒; 在网络、硬件 符合应用系统配置要求的前提下, 非统计性查询 响应时间 $\leqslant 3$ 秒，统计性查询响应时间 $\leqslant 10$ 秒;

4) 系统必须稳定地不间断运行, 不能出现由于系统 自身原因造成服务中断; 
5) 具有较强的容错能力, 即使用户出现错误操作或 操作系统错误, 也不会导致数据的丢失或不一致 性;

6) 报错信息必须清晰可理解;

（2）易用性需求

1) 用户界面简单清晰，符合操作人员的习惯，减少 重复信息的录入;

2) 系统应提供综合的业务综合信息查询功能，并支 持全文检索及信息模糊查询功能, 以方便用户查 询和使用系统;

\section{3. 开发和维护需求}

1) 支持二次开发且不影响既有系统功能;

2) 系统的任何升级或补丁更新需要提供版本管理, 并且不得影响正常业务处理, 并可以退回至上一 节点;

3) 拥有归档管理机制和工具, 对长期不使用的数据 提供导出和再导入功能, 对于结构化数据和非结 构化数据进行统一归档;

\section{4. 用户权限需求}

1）提供用户的权限管理功能, 并且可以和企业挂钩, 支持多级授权 [5];

2）系统内所有权限分配的操作必须方便，支持权限 继承，可以批量进行分配权限;

3) 用户在权限范围内, 可自行维护本级相关数据, 例如: 字典数据;

\section{5. 兼容性和升级需求}

1) 具有失效恢复能力及容错能力, 能方便地追溯故 障所在;

2) 所有的二次开发内容及系统补丁必须与产品兼容, 系统的打补丁、升级等不会导致二次开发内容的 应用出现问题;

3) 除了操作系统和数据库本身之外, 系统应提供运 行日志;

4) 应充分考虑浏览器兼容性问题, 确保系统适应不 同版本浏览器 $[6]$;

\section{4. 系统概述}

\section{1 . 总体设计}

系统采用B $/ \mathrm{S}$ 架构。

系统采用两级应用、一级集中部署方式。

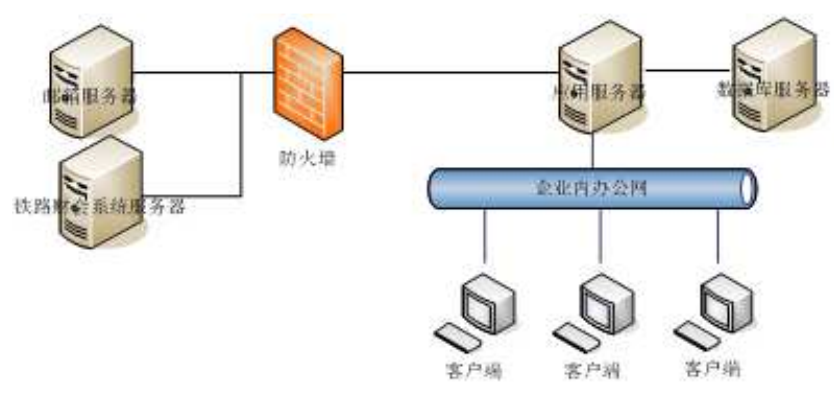

图1 系统网络部署图。

在实际应用中，系统支持集权管理和分权管理两种 模式。集权管理是指只有集团总部有权限维护系统相关 功能或数据等配置, 各个所属的企业继承使用, 不可以 自定义维护; 分权管理是指各个所属企业可在继承总部 相关数据之后, 在权限范围内维护本级数据。

在实际部署中，采用集团总部集中部署，各所属企 业用户访问的方式，该技术方案具有信息集中共享效率 高、维护方便等特点。

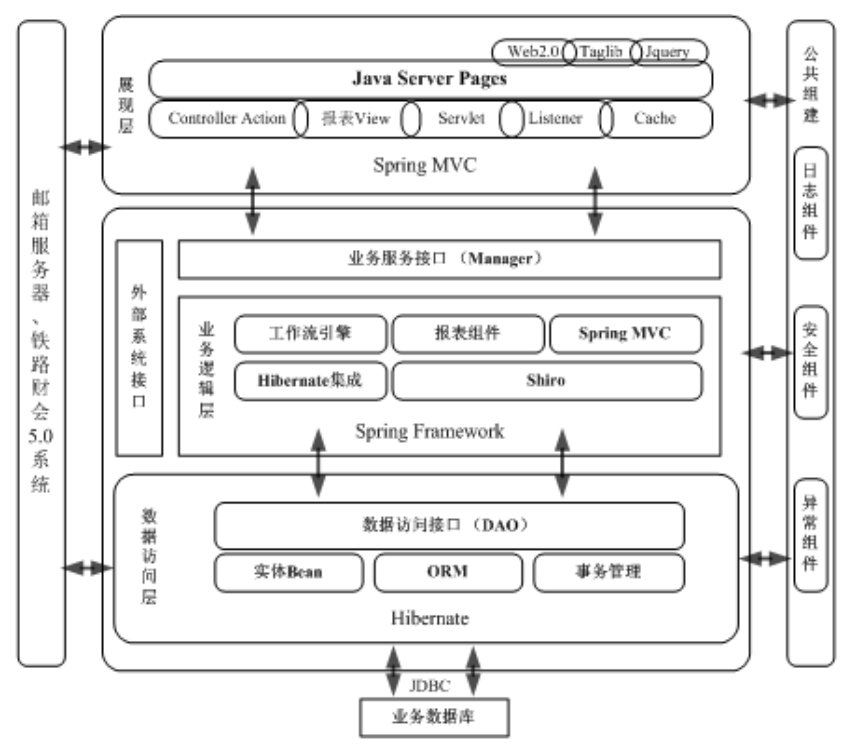

图2 统技术架构图。

由图可见, 系统采用三层开发架构, 将系统的整个 业务应用划分为展现层, 业务逻辑层和数据访问层, 从 而实现 “高内聚, 低耦合”, 有利于系统的开发、维护、 部署和扩展 $[7]$ 。其中:

1) 展现层

作为用户与系统的交互层, 将业务逻辑层的信息全 方位、多角度的展现在用户面前, 通过审批、穿透查询、 统计汇总等功能的综合运行和集成作业, 为薪酬管理的 各级用户提供高效处理和分析业务层信息的管理工具和 平台。

2) 逻辑层

业务逻辑层是系统架构中体现核心价值的部分。它 的关注点主要集中在与薪酬管理业务需求有关的系统设 计, 包括发放规则的制定、业务流程的实现。同时在这 一层, 通过接口实现与外部系统的业务集成和数据传输, 
例如：与外部的邮箱系统集成，实现工资条的发放; 与 铁路财务系统的集成，实现工资凭证的传递和人工成本 的核算与分摊等 $[8]-[9]$ 。

\section{3) 数据层}

依赖于Hibernate的对象化映射和数据库交互, 处理 $\mathrm{DA} 0$ 组件请求的数据, 并返回处理结果, 从而实现对数据 的增删改查等操作。

\section{2. 核心规则设计}

1) 定义不同账户下的工资项

首先在规则配置之前, 需要为不同的账户（账套） 维护工资项字典, 定义工资项的名称、属性等信息。之 后, 为每一个处于工资项字典的末级工资项配置发放/扣 减规则。这样设计, 既可以保证不同账户下工资项字典 的自定义灵活扩展，也可以保证该工资项可以通过规则 在系统中自动进行计算, 确保了数据流的可行性。与此 同时，分账户配置工资项也直接生成了该账户下工资条 的内容，这样即可实现自定义工资条的内容。

\section{2) 规则配置}

将与工资项发放/扣减规则有关的要素定义为变量, 选取变量和变量间的逻辑关系进行组合，生成表达式; 再选择表达式与表达式之间的逻辑关系进行组合, 生成 工资项发放/扣减规则。这样设计, 可以保证规则的灵活 配置，可推广价值高。具体如下:

\section{表达式=变量+逻辑关系; \\ 规则 $=$ 表达式+逻辑关系;}

举例1：部标岗位工资依照铁总文件规定，根据员工 的岗位系数而定，标准举例如下:

表1 部标岗位工资区间标准（举例）。

\begin{tabular}{lllll}
\hline 岗位系数分档 & 1.6 以下 & $1.6-1.7$ & $1.8-1.9$ & $\ldots \ldots$ \\
\hline 岗位工资标准 & $\mathrm{A}$ & $\mathrm{B}$ & $\mathrm{C}$ & $\ldots \ldots$ \\
\hline
\end{tabular}

因此, 部标岗位工资是以岗位系数为基本，按区间 发放的。

综上所述，部标岗位工资与人员类别和岗位系数有 关, 那么 “人员类别” 和 “岗位系数” 即可作为变量, 通过逻辑关系生成表达式1和表达式 2 , 再组合成为规则 1 , 即： $1.6<=$ 岗位系数 $<=1.7$ 的编制内员工, 部标岗位工资 按每月 $B$ 元每人的规则进行发放。规则配置如下所示:

表2 规则配置。

\begin{tabular}{|c|c|c|c|}
\hline \multicolumn{4}{|l|}{ 部标岗位工资 } \\
\hline 规则1名称: & \multicolumn{3}{|c|}{$\begin{array}{l}\text { 编制内员工岗位系数大于等于 } 1.6 \text { 并且小于等于 } \\
1.7 \text { 的部标岗位工资发放 }\end{array}$} \\
\hline $\begin{array}{l}\text { 规则 } 1 \text { 描述: } \\
\text { 表达式配置 }\end{array}$ & \multicolumn{3}{|c|}{ 发放B元每月 } \\
\hline $\begin{array}{l}\text { 表达式1 } \\
\text { 与 }\end{array}$ & 人员类别 & 等于 & 编制内 \\
\hline $\begin{array}{l}\text { 表达式2 } \\
\text { 与 }\end{array}$ & 岗位系数 & 大于等于 & 1.6 \\
\hline $\begin{array}{l}\text { 表达式3 } \\
\text { 发放 }\end{array}$ & $\begin{array}{l}\text { 岗位系数 } \\
\text { B }\end{array}$ & \multicolumn{2}{|c|}{ B } \\
\hline
\end{tabular}

能够通过规则配置的工资项均可进行规则配置, 此 后按此规则在系统中自动运算。以上可配置的工资项均 已在数据库中得到验证, 可转换为相应的SQL语句, 保证 了核心算法的可行性。

\section{3. 功能设计}

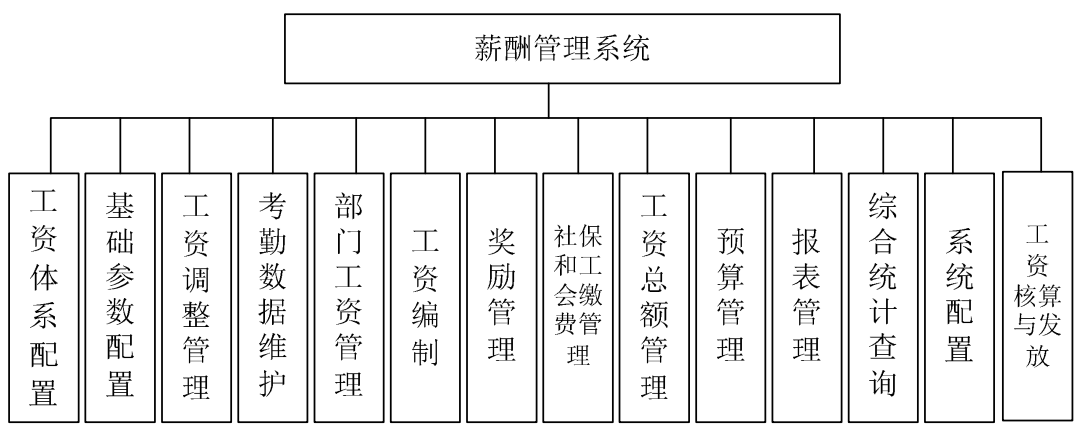

图3 统功能架构图。

（1）工资体系配置

该功能是系统的核心部分，包括分账户工资项字典 的维护、工资项发放规则的维护。其中:

A分账户工资项字典维护可实现:

1) 不同账户下工资结构的新增、修改、停用;

2) 工资结构下发放和扣款工资项的新增、修改、停 用;

3）工资项是否需要部门上报的属性配置;

4）分账户工资项配置直接生成该账户下的工资条内 容;
B 工资发放规则维护可实现:

1) 对已维护的工资项进行发放/扣款的规则配置;

2) 对已配置的规则进行预览、准确性校验;

（2）基础参数配置

该功能包括岗位工资基数、地方最低工资标准、不 同账户的五险一金扣缴比例以及上下限参数等维护。

（3）工资调整管理

该功能用于人资薪酬负责人维护和管理薪酬业务中 涉及的工资调整变动, 以及由此产生相关的工资通知单。 包括员工入职工资通知单、员工离职工资通知单、员工 
定岗通知单、员工岗位变动工资通知单、员工工资调整 通知单、领导干部工资变动通知单; 同时通过这些审批 后的通知单, 触发系统中相应指标、参数等信息的变更, 例如人员属性信息的自动变更。

（4）考勤数据维护

该功能主要对实现与企业既有考勤打卡系统对接, 获取并维护考勤数据, 下发至各部门。

（5）月度部门工资管理

该功能主要用于各部门的月度工资管理，包括部门 月度绩效维护、部门绩效表下发、汇总三个环节。主要 用于人资薪酬负责人维护各部门每个月可调控的绩效额 度、可累计使用的剩余金额; 之后将部门绩效表下发至 各部门进行填报, 最后人资部统一汇总生成绩效总表。 这一功能涉及到多个部门的业务交互和数据共享。

（6）月度工资编制

该功能用于人资薪酬负责人按照不同账户（每个企 业存在多账套情况）进行月度工资编制。包括：

1）根据前期的工资体系配置、月度各部门工资维护 等工作，最终分账户汇总本月所有工资项，由系 统自动计算相应金额，发送至财务系统;

2) 根据权限支持部分工资项数据的即时修改;

(7) 奖励管理

该功能主要用于维护奖励类型信息, 包括人才津贴、 项目/团队获奖奖励、结题奖、年终考核奖等。支持跨部 门奖励数据编制、申报。该功能涉及到多个部门间的业 务交互和数据共享。

（8）社保和工会缴费管理

该功能包括每个人的五险一金缴纳基数维护、个人 企业年金维护、个人工会会费维护。其中:

A五险一金缴纳基数维护:

1）根据员工上年度收入，自动计算员工工资申报基 数;

2) 根据员工月均收入、缴费基数上下限, 自动计算 员工缴费基数;

3) 按照参数配置中的缴纳比例自动生成员工五险一 金的缴纳金额调整表;

4）根据生效日期, 在相应月份自动参与工资编制;

$\mathrm{B}$ 企业年金缴纳基数维护:

1）根据员工工龄属性的变更，自动更新员工企业年 金的缴纳金额;

2) 维护企业年金调整的生效日期，在相应月份自动 参与工资编制;

3）自动计算补扣金额;

C工会会费维护:

1) 维护调整的生效日期、扣缴比例、每个员工的扣 缴基数;

2) 根据比例自动计算扣缴金额, 并计算补扣金额;

3）根据生效日期，在相应月份参与工资编制;

（9）工资总额管理

该功能包括工资总额维护、工资总额执行监控、工 资总额预测。其中:

A工资总额维护:

1) 分不同账户维护工资总额的起止日期、计划总额;
2) 记录工资总额维护日志;

B工资总额执行监控:

1) 对不同账户的工资总额进行监控, 通过对发放情 况进行汇总, 判断是否超总额预算;

2) 显示已发放和剩余可用的工资数额占工资总额的 比例;

（10）预算管理

该功能主要用于维护年度人工成本预算信息。

(11) 工资核算与发放

该功能用于财务部门对人资部传递的工资明细数据 进行相关扣税核算 [10], 并对明细数据分账户、分部门 汇总, 最终将个人工资数据结果通过邮件发送至员工本 人。其中:

A扣税核算:

1) 根据核算算法, 分账户对人资部提供的工资明细 数据进行税款核算，得到应税、实发金额;

2) 生成员工个人的工资条, 并通过邮件发送工资条 至员工本人;

B对明细工资数据汇总:

1) 分账户、分部门进行汇总, 生成满足财务需求的 数据表格;

2) 支持汇总数据的导出;

C导出银行报盘凭证:

1）从工资实发结果中，根据模板导出银行报盘凭证;

2) 将凭证数据传递给铁路财会系统;

（12）报表管理

该功能主要用于维护月度、季度、年度报表, 包括:

1）员工月基础工资、年收入、年度奖金统计报表;

2) 支持在线自定义报表的制定;

（13）综合统计查询

该功能可依据用户需求, 提供多维度、多角度的综 合查询统计。支持查询统计信息的Excel文件导出。

(14) 系统配置

$\mathrm{A}$ 表单配置

1）该功能支持用户在线自定义制定表单，例如通知 单、申请单、审批单等;

2）支持已制定的表单与流程绑定，在流程中调取相 应的表单信息;

B流程配置

1）该功能支持用户在线自定义制定审批流程，例如 绩效调整申请、奖励发放申请等;

2）支持在流程中对应相应的表单;

C权限配置

该功能用于配置用户--角色--功能权限。

D日志查询

该功能用于记录系统运行日志, 便于系统维护人员 查询。

\section{4. 接口设计}

薪酬管理信息系统能够提供统一的内部、外部接口 方案。其中, 内部接口应涵盖企业内部其他应用系统, 例如铁路成本管理系统、铁路财会系统等路内自有系统; 
同时, 能够提供统一接口协议, 满足与外部系统的对接, 例如企业自有 $\mathrm{OA}$ 等办公系统, 从而满足企业各级部门的 管理需求。

\section{5. 小结}

（1）搭建中国铁路企业集中统一薪酬管理平台 统一集成的薪酬管理平台能够充分改变人资部门信 息基础薄弱、没有电子化数据化的现状, 消除各部门数 据分散的弊端, 实现人员、工资等数据信息在企业范围 内的有效共享。

（2）规范优化业务流程

借助系统的建设实施, 对相关基础数据、基础数据 标准、核心业务流程、审批单据在集团范围内进行统一 梳理和优化。

(3) 提升工作效率

(4) 加强实时集团管控

系统通过实时、准确的反映各部门工资制定、下达、 执行、反馈情况，提高了薪酬管理的透明度。

（5）支撑战略决策分析

系统通过提供相关标准化算法规则、常用报表以及 灵活查询工具, 实现对领导班子、组织机构、员工总量、 员工工资结构等的情况统计和多维度分析。

\section{参考文献}

[1] 沈静. 从国有企业的视角研究薪酬管理 [J]. 生产力研究, 2010 (2) : 211-212.

[2] 铁路总公司. 铁路财会信息化总体规划 [D]. 北京：2012.

［3］铁路总公司劳卫部. 中国铁路总公司关于调整企业职工岗 位工资标准的通知（铁总劳卫部 [2015]14号） [D]. 北京: 2015.

[4] 黄浪. 企业级的 $\mathrm{B} / \mathrm{S}$ 模式应用软件非功能性需求分析与研究 [D]. 福建: 厦门大学, 2008: 33-47.

[5] 张川波. Web统一用户权限控制模型的研究与设计 $[D]$. 上海: 上海交通大学，2007:9-44.

[6] David Flanagan. JavaScript权威指南 [M]. 淘宝前端团队, 译. 机械工业出版社, 2012:326-332.

[7] 戴克. Spring MVC学习指南 [M]. 林仪明, 崔毅 译. 人民邮 电出版社, 2015:56-187.

[8］李海波. 会计学原理 [M]. 立信会计出版社, 2011:186-207.

[9] 文洋, 尹凤霞. SAP从入门到精通 [M]. 人民邮电出版社, 2015:151-181.

[10] 吉燕. 用友ERP-U8 [M]. 清华大学出版社, 2012:279-322. 